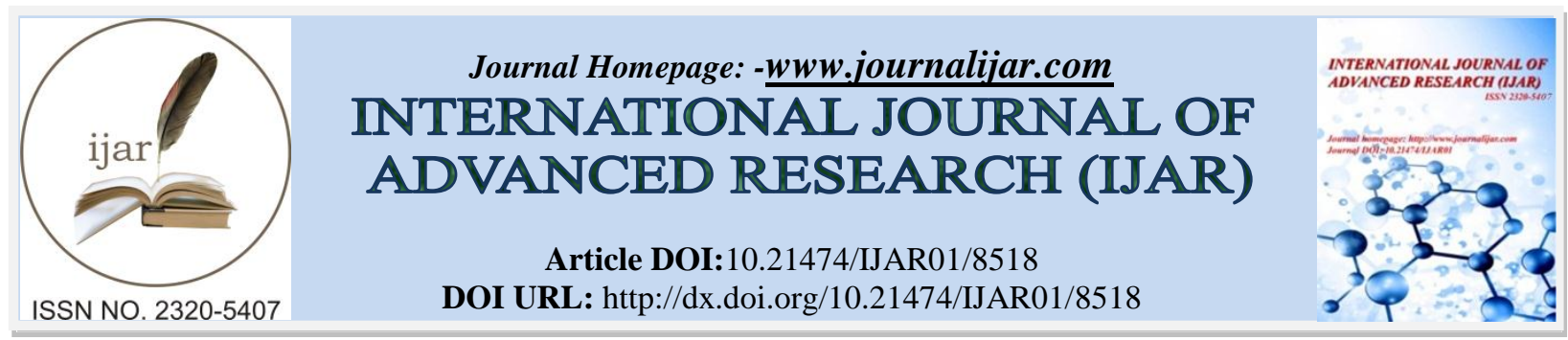

RESEARCH ARTICLE

\title{
KNOWLEDGE DONATING \& COLLECTING ACTIVITIES AMONGST MULTI-GENERATIONAL FACULTY MEMBERS.
}

Priyanka Saxena and Ranjan A. John.

Sam Higginbottom University of Agriculture Technology \& Sciences, Allahabad (U.P.), India.

\section{Manuscript Info}

\section{Manuscript History}

Received: 06 December 2018

Final Accepted: 08 January 2019

Published: February 2019

Key words:-

Knowledge Donating Activities,

Knowledge Collecting Activities,

Multi-generational faculty members.

\begin{abstract}
Indian Higher Education sector now encompasses three generation faculty members. With advancement in the global business scenario education system reforms to deal with this dynamic situation is the need of the hour. All the business corporations are designing their strategies to tackle the problems related to generational workforce and extract maximum talent from different generation workforce. In this line higher education also needs to inline their interest in generational issues of faculty members. One of the issues dealt in this paper is sharing knowledge amongst different generations since all the generation have their characteristic differences so their knowledge giving and knowledge taking behavior and frequency also differs. The data collected from different universities and colleges of Allahabad and Lucknow revealed that the three generations are different in knowledge donation and knowledge collection. The frequency of the activities was also measured and was found that it was different within the university or college as compared to outside the institution. Generation $\mathrm{Y}$ were more active outside their university/college and on the other hand Generation $\mathrm{X}$ were more active in their university/college. Further Baby boomers showed the minimal difference in knowledge activities within and outside the university/ college. It was suggested that light interaction amongst all the generation will help to foster a work culture where the flow of knowledge donation and collection can take place.
\end{abstract}

Copy Right, IJAR, 2019,. All rights reserved.

\section{Introduction:-}

The education system in India reached a different level with the joining of fresh graduates and postgraduates. This sector unlike corporates now a pool of multi-aged as well as multi-talented people. The term multigenerational faculty members in this research paper are a hybrid form of knowledge pool from different age groups. Each generation is having something different to serve to the institution. Today those institutions are leading which have understood and developed a system to extract knowledge and skills of different generations. On the basis of a review of the literature, it has been found that there are certain generational characteristics which are distinct in every generation. It has been found that the basis of formation of these different characters is different experiences, political environment, economic environment, and social environment faced by these generations in their times. These different experiences are the cause of generational behavior difference.

Corresponding Author:-Priyanka saxena.

Address:-Sam Higginbottom University of Agriculture Technology \& Sciences, Allahabad (U.P.), India. 
Therefore it becomes important to understand how these people belonging to different generations disseminate their knowledge. The study focused their knowledge behavior within the university or college and outside their university or college. Here outside university or college specifically means other universities or colleges. The two aspects of Knowledge behavior are studied in this study namely knowledge donating activities and knowledge collecting activities. The two dimensions of knowledge that is tacit and explicit knowledge are very important when it comes to knowledge sharing (Zaquot \& Abbas, 2012)

\section{Knowledge Donating and Knowledge Collecting activities}

(Vries \& Hoff, 2006)Two components of knowledge behavior that is knowledge giving and knowledge taking termed as donating and collecting. Found that eagerness and willingness are important for sharing knowledge as both the factors were positively related to the sharing of knowledge. (Mansor \& Mustaffa, 2015)Willingness is explained as how much the person is ready so that others can access his or her knowledge keeping others point of view in consideration whereas eagerness does not consider what others interest is, it simply focus on sharing. So individuals who are willing to share keep maintain equilibrium what knowledge they are giving and what they are getting. It was further stated that one of the factors which contribute to the willingness of sharing knowledge is communication.

\section{Multi-Generational faculty members}

With the development of education, there is a rapid increase in job opportunities. The government also emphasizing on higher education, training and other courses which are very important for being employable. The higher education sector in India recently became the new interest area for youngsters and they are joining in their early stage of career. (Frolich \& Stensaker, 2010)This knowledge pool of diverse age group faculty members has been identified as an innovative strategy to cater to dynamic business requirements. (Reid \& Moore, 2008)Gone are the days when corporate give intensive training now they are looking for ready to work individuals. This is only possible when the education system can enforce concept as well as its applicability to their students.

\section{Review of Literature}

(Johnson \& Romenallo, 2005) the article discussed that diverse age group trainers can impart knowledge in different areas and different styles, as each generation have some or the other uniqueness. (Austin, 2016) it was discussed that since parents and companies want their children employable so they are looking for education which can get a job after the completion of the course. In this context, the latest subject matter should be related to facts and concepts given in the books. (Bhusry \& Ranjan, 2012)Knowledge should make students not only to pass the exams but also to get them employment. (Bliuc \& Goodyear, 2007)Also, these days with the rapid change in technology and other societal changes students demanding education should be imparted to them in innovative ways. Senior faculty members who are having their command on concepts but are little hesitant to adopt new technology and on the other hand young faculty members whose strength is technology can work together. (Price \& Kirkwood, 2013)The need of the hour is to have a mix of both books and technology which is only possible with diverse age group faculty members. This relation can only be build when there will be an understanding of all generations characteristics and celebrating their strengths. (Lin, 2007) it was empirically discussed that flow of knowledge is affected by many factors some are related to personal factors of the individuals, some related to their age group they belong and some are institutional factors. But whatever be the reason it was suggested that in order to achieve goals of the institution it is important to understand the diversity of age. There are certain factors which inspire people to share their knowledge and on the other hand, there are certain reasons which refrain people not to indulge in this process. The success of the organization depends on how much these problems are addressed. It is crucial that people should give or share their expertise as well as learn new knowledge. (Susanty \& Wood, 2011) The study was conducted in Telecommunication in Indonesia to understand that there are certain components for motivating employees to share their knowledge. These were divided into extrinsic and intrinsic components for sharing knowledge. The study established a relationship between the factors using t-test. (Husseini \& Elbeltagi, 2015) It was considered important to build a relationship between faculty members to achieve give and take of knowledge. AMOS model was developed to show a positive relationship of knowledge sharing with the development of new practices. Learning can only be nurtured when an environment of encouragement and innovation will go hand in hand. (Chen, 2010) Certain factors which are important and which is why people share knowledge are having trust (Holste, 2009)or feeling safe to share knowledge, people tend to share knowledge with those who are having a similar mindset. (Gho, 2002)But in order to build a virtual knowledge database, it is important to encourage people to share knowledge. (Landoli \& Quinto, 2012)Feedback always play a role in enhancing knowledge flow. (Dumey \& Garletti, 2015)based on 
many research journal it was found that there are differences in problems related to management of knowledge with respect to location, age, type of sector; public or private sector. So it is important to consider this fact als o that there cannot be a set strategy to deal with the problem. (Kamasak, 2010) two forms of knowledge that are giving and taking; knowledge collecting is affected by technological factors whereas knowledge donation is effected by groups, type of relationship between the receiver and giver. (Tessie H.H. Herbst, 2011) Leaders should not only encourage people to share knowledge but also they should inspire them to share knowledge with their actions. (Zaquot \& Abbas, 2012) two forms of knowledge that are tacit knowledge and explicit knowledge is important for learning amongst students. (Ding \& Xue, 2015) It was discussed that tacit knowledge directly impacts performance as it is an action of the individual.

\section{Objectives of the study}

The main objective of the study is to find out are there any differences in knowledge behavior of different age faculty members. And also to explore faculty members behave differently within their university or college they are working and other university or college when it comes to sharing their expertise.

\section{Research Methodology:- \\ The Study}

The study is descriptive in nature with the survey method used for collecting the information and data through a self-designed questionnaire.

\section{Sampling Design}

1. Population: Faculty members of different age.

2. Sampling frame: Faculty members working in different universities and colleges of Prayagraj (Allahabad) and Lucknow

3. Sample size: 383 respondents

4. Sample elements: Individual faculty member is the sample element.

5. Sampling Techniques: Purposive sampling technique used to collect the data.

Tools for data collection: Self-designed questionnaire

Questions were formed in such a manner that both KDA and KCA are covered and their frequency can also be measured. KDA within the University or college termed as A1 and KDA outside the university termed A2. Also, KCA within the University or college termed as A3 and KCA outside the university termed A4.

Multi-Generational faculty members responded to the questionnaire which asked questions regarding their knowledge activities. The responses were tabulated and analyzed.

Table 4.3a:-Knowledge Donating Activities (KDA) amongst Multigenerational faculty members

\begin{tabular}{|l|l|l|l|}
\hline & Within the University/ College & & Outside the University/ College \\
\hline A1(a) & $\begin{array}{l}\text { Storytelling during social gathering/ while } \\
\text { working }\end{array}$ & A2 (a) & $\begin{array}{l}\text { Storytelling during social gathering/ while } \\
\text { working }\end{array}$ \\
\hline A1(b) & Face to face communication & A2 (b) & Face to face communication \\
\hline A1(c) & I share my knowledge on Phone Calls & A2 (c) & I share my knowledge on Phone Calls \\
\hline A1(d) & I send messages (Eg. Whats app groups) & A2 (d) & I send messages (Eg. Whats app groups) \\
\hline A1(e) & $\begin{array}{l}\text { I give Lectures/ Presentations in Formal } \\
\text { Events }\end{array}$ & $\begin{array}{l}\text { A2 (e) } \\
\text { Events }\end{array}$ \\
\hline
\end{tabular}

Table 4.3b:-Knowledge Collecting Activities (KCA) amongst Multigenerational faculty members

\begin{tabular}{|c|c|c|c|}
\hline & Within the University/ College & & Outside the University/ College \\
\hline A3(a) & $\begin{array}{l}\text { I listen to experiences, an opinion shared } \\
\text { by colleagues in social gathering/ working. }\end{array}$ & A4(a) & $\begin{array}{l}\text { I listen to experiences, an opinion shared } \\
\text { by colleagues in social gathering/ working. }\end{array}$ \\
\hline A3(b) & Face to face communication & A4(b) & Face to face communication \\
\hline A3(c) & I attend phone calls & A4(c) & I attend phone calls \\
\hline A3(d) & I read messages (Eg. Whats app groups) & A4(d) & I read messages (Eg. Whats app groups) \\
\hline$\overline{A 3}(\mathbf{e})$ & $\begin{array}{l}\text { I listen to Lectures/ Presentations in } \\
\text { Formal Events }\end{array}$ & A4(e) & $\begin{array}{l}\text { I listen to Lectures/ Presentations in Formal } \\
\text { Events }\end{array}$ \\
\hline
\end{tabular}


Tools for data analysis:

Reliability: Cronbach's alpha

\begin{tabular}{|c|c|}
\hline Cronbach's Alpha & N of Items \\
\hline .810 & 20 \\
\hline
\end{tabular}

\section{Validity}

The validity of the questionnaire was measured through face to face interaction method and was found to be high.

\section{Percentage analysis}

Table 4.5 a:-Percentage of Knowledge Donating Activities within and outside the University/ College

\begin{tabular}{|l|l|l|l|l|l|l|l|l|l|l|}
\hline \multicolumn{9}{|l|}{ Within the University/ College } & \multicolumn{4}{l|}{ Outside the University/ College } \\
\hline KDA in \% & $\mathbf{A 1}(\mathbf{a})$ & $\mathbf{A 1}(\mathbf{b})$ & $\mathbf{A 1}(\mathbf{c})$ & $\mathbf{A 1}(\mathbf{d})$ & $\mathbf{A 1}(\mathbf{e})$ & $\mathbf{A 2}(\mathbf{a})$ & $\mathbf{A 2}(\mathbf{b})$ & $\mathbf{A 2}(\mathbf{c})$ & $\mathbf{A 2}(\mathbf{d})$ & $\mathbf{A 2}(\mathbf{e})$ \\
\hline Baby Boomer & $\mathbf{6 6 . 1}$ & 35.5 & 24.9 & 21.9 & $\mathbf{7 3 . 8}$ & $\mathbf{6 6 . 8}$ & 34.7 & 25.2 & 22.0 & $\mathbf{7 5 . 2}$ \\
\hline Gen X & 22.5 & $\mathbf{4 8 . 1}$ & 29.4 & 19.5 & 19.5 & 19.9 & $\mathbf{4 7 . 4}$ & 37.3 & 28.9 & 11.7 \\
\hline Gen Y & 11.4 & 16.4 & $\mathbf{4 3 . 4}$ & $\mathbf{4 8 . 7}$ & 6.7 & 13.3 & 17.9 & $\mathbf{3 7 . 5}$ & $\mathbf{4 9 . 1}$ & 13.1 \\
\hline
\end{tabular}

\section{Interpretation}

On the basis of the above table, there is a significant difference between the three generations with respect to Knowledge Donating Activities. Also, it's been clearly shown that Knowledge Donating behavior of the same group is different when it is within the University/ College and when it is outside the University/ College. However, the difference in KDA behavior is very small amongst the same group.

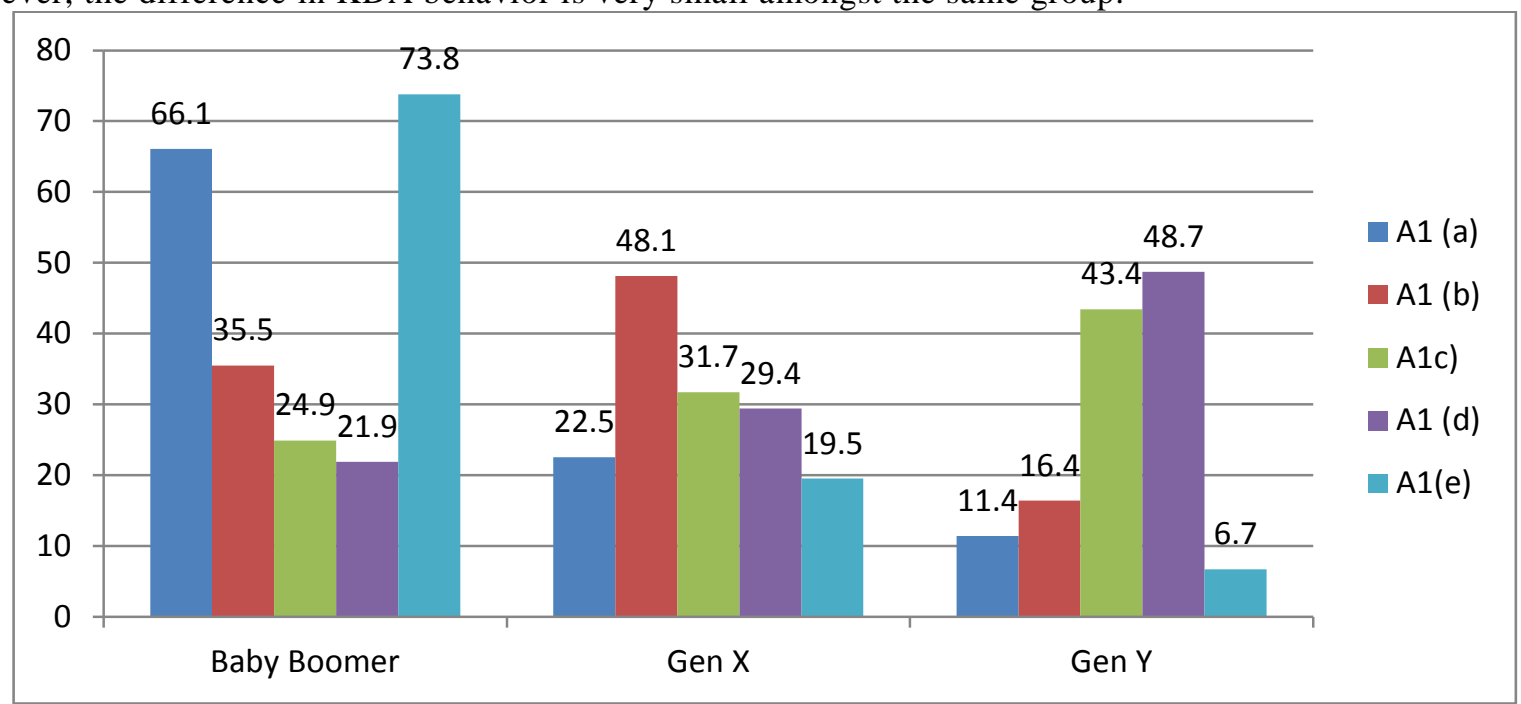

Chart 4.5 a.1:-Graphical Representation of Knowledge Donating Activities (KDA) amongst Multigenerational faculty members within the University/ College 


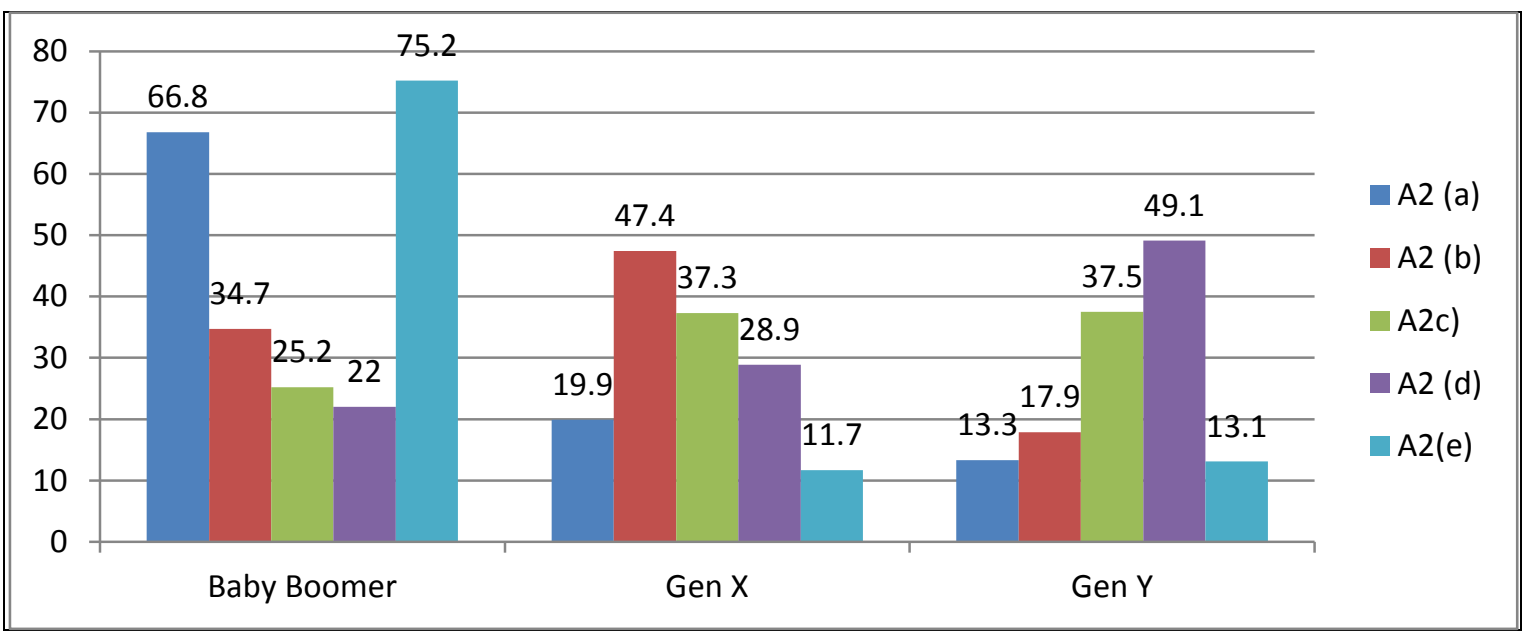

Chart 4.5 a.2:-Graphical Representation of Knowledge Donating Activities (KDA) amongst Multigenerational faculty members outside University/ College

Table 4.5 b:-Percentage of Knowledge Collecting Activities within and outside the University/ College

\begin{tabular}{|l|l|l|l|l|l|l|l|l|l|l|l|}
\hline \multicolumn{10}{|l|}{ Outside the University/ College } \\
\hline $\begin{array}{l}\text { KCA in } \\
\%\end{array}$ & $\mathbf{A 3}(\mathbf{a})$ & $\mathbf{A 3}(\mathbf{b})$ & $\mathbf{A 3}(\mathbf{c})$ & $\mathbf{A 3}(\mathbf{d})$ & $\mathbf{A 3}(\mathbf{e})$ & $\mathbf{A 4}(\mathbf{a})$ & $\mathbf{A 4}(\mathbf{b})$ & $\mathbf{A 4}(\mathbf{c})$ & $\mathbf{A 4}(\mathbf{d})$ & $\mathbf{A 4}(\mathbf{e})$ \\
\hline $\begin{array}{l}\text { Baby } \\
\text { Boomer }\end{array}$ & $\mathbf{6 5 . 4}$ & 33.6 & 27.6 & 21.3 & $\mathbf{6 6 . 8}$ & $\mathbf{5 9 . 3}$ & 34.2 & 29.4 & 29.8 & $\mathbf{6 8 . 9}$ \\
\hline Gen X & 17.9 & $\mathbf{5 1 . 7}$ & $\mathbf{4 5 . 1}$ & 32.3 & 14.7 & 15.6 & $\mathbf{3 7 . 8}$ & 33.7 & 26.3 & 10.4 \\
\hline Gen Y & 16.7 & 14.7 & 27.3 & $\mathbf{4 6 . 4}$ & 18.5 & 25.1 & 28 & $\mathbf{3 6 . 9}$ & $\mathbf{4 3 . 9}$ & 20.7 \\
\hline
\end{tabular}

\section{Interpretation}

On the basis of the above table, there is a significant difference between the three generations with respect to Knowledge Collecting Activities. Also, it's been clearly shown that Knowledge Collecting behavior of the same group is different when it is within the University/ College and when it is outside the University/ College. However, the difference in KCA behavior is very small amongst the same group.

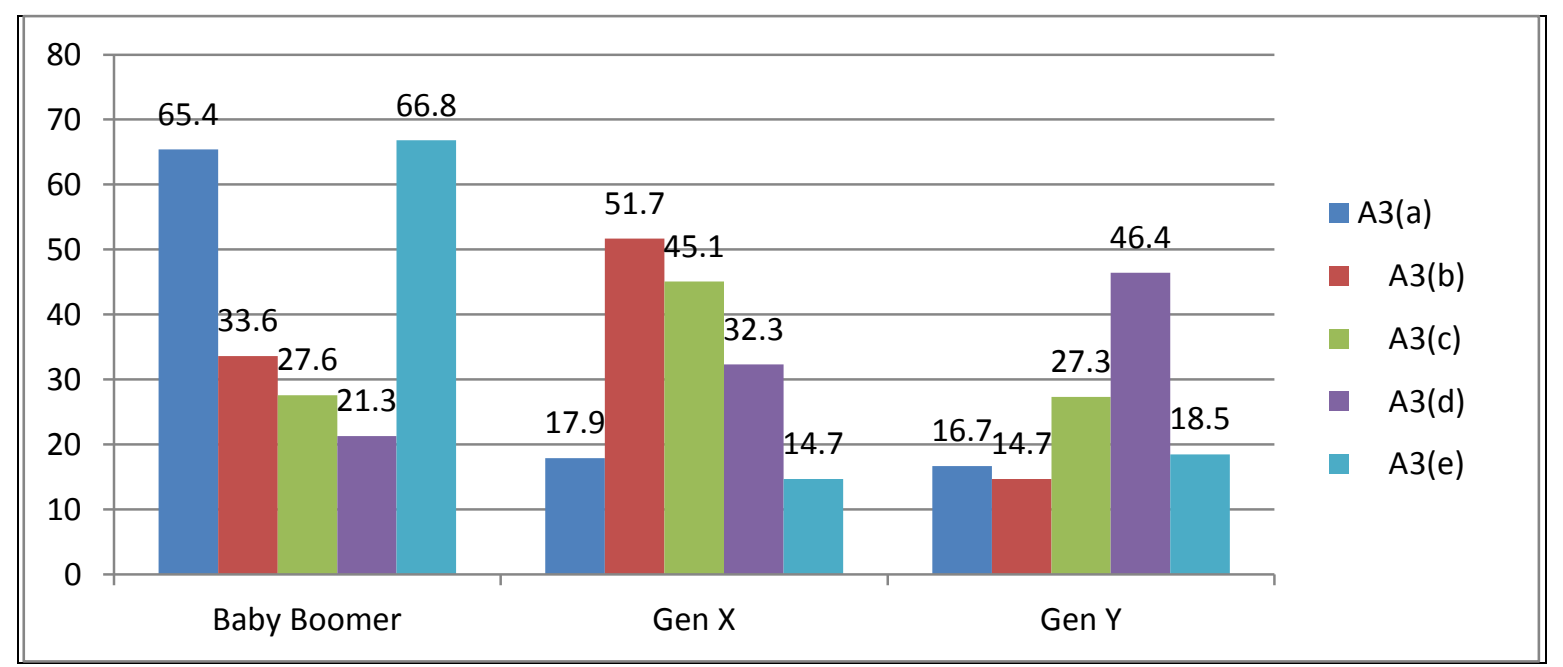

Chart 4.5 b.1:-Knowledge Collecting Activities (KCA) amongst Multigenerational faculty members within the University/ College 


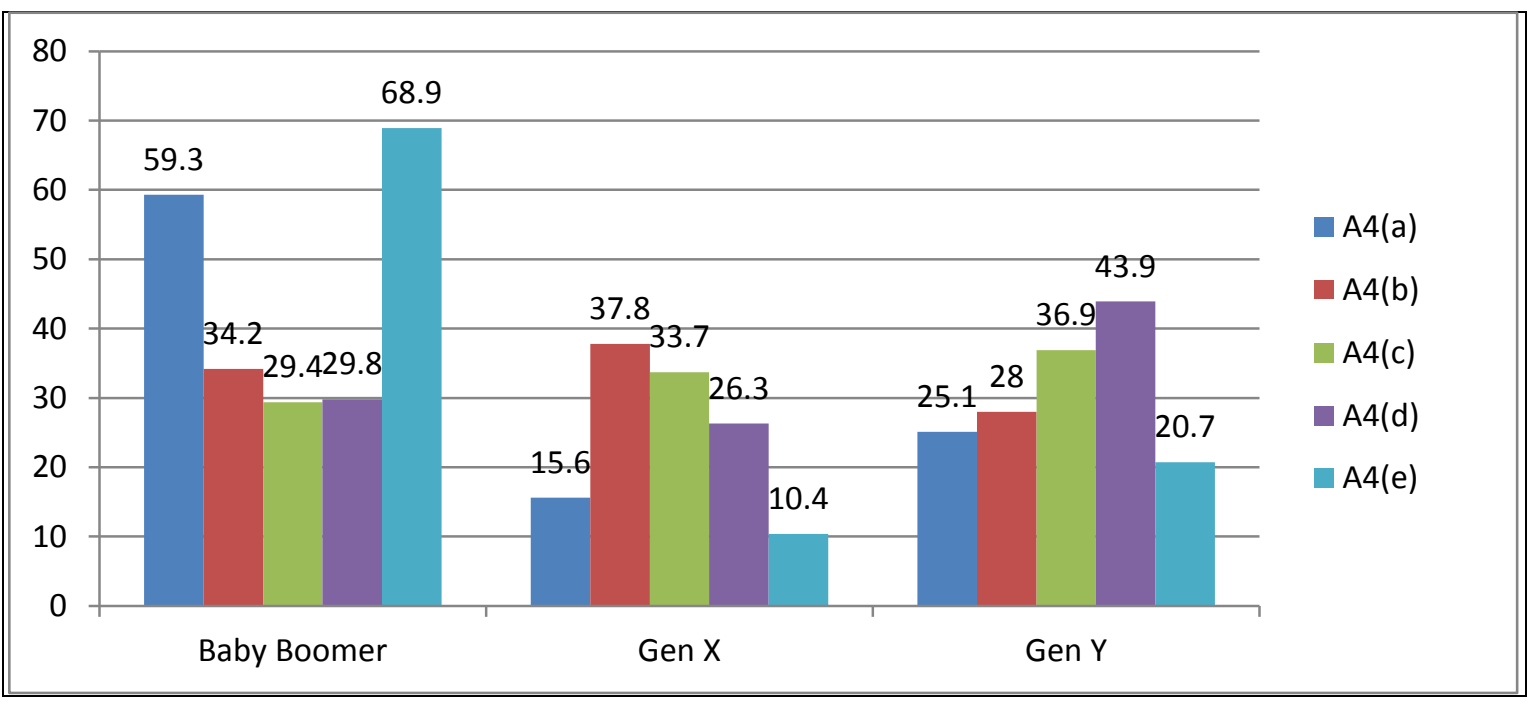

Chart 4.5 b.2:-Knowledge Collecting Activities (KCA) amongst Multigenerational faculty members outside the University/ College

It can also be seen that there is a difference in KDA and KCA of the three generations.

\section{Justification of the study}

The study will help in understanding one of the magnitudes of knowledge that is tacit knowledge. Dissemination of tacit knowledge takes the road of contributing and taking knowledge. This is termed as KDA (Knowledge Donating Activities) and KCA (Knowledge Collecting Activities). Tacit knowledge forms the basis of explicit knowledge. All the faculty members having unique tacit knowledge and therefore it is important to store their tacit knowledge before they leave the organization. Tacit knowledge gives the institutions a competitive edge. So in order to be a leading institution, it is important to disseminate tacit knowledge within the institution as well as outside the institution.

\section{Results and Discussions:-}

Knowledge Donating Activities

1. Baby Boomers showed highest percentage in storytelling that is $66.1 \%$ and $66.8 \%$ within the institution and outside the institution respectively. They have also showed highest percentage in giving Lectures/ Presentation within and outside the institution $73.8 \%$ and $75.2 \%$. However their lectures/presentations are slightly higher outside the institution when compared to within the institution. Most probably the reason could be their networking with other institutions.

2. Face to face interaction is high amongst Generation $\mathrm{X}$ with $48.1 \%$ within the institution and $47.4 \%$ outside the institution.

3. Generation $\mathrm{Y}$ showed highest percentage in phone calls $43.4 \%$ and $37.5 \%$ within the institution and outside the institution respectively. Also sending messages $48.7 \%$ and $49.1 \%$ within the institution and outside the institution respectively.

\section{Knowledge Collecting Activities}

1. Baby Boomers showed highest percentage in listening to experiences and opinions that is $66.4 \%$ and $59.3 \%$ within the institution and outside the institution respectively. They have also showed highest percentage in giving Lectures/ Presentation within and outside the institution $66.8 \%$ and $68.9 \%$. However their lectures/presentations were slightly higher outside the institution when compared to within the institution probably because of their connected to other faculty members.

2. Face to face interaction is high amongst Generation $\mathrm{X}$ with $51.7 \%$ within the institution and $37.8 \%$ outside the institution. Result reflecting that they are interactive within the institution However the result for attending phone calls $45.1 \%$ outside the institution and $33.7 \%$ within the institution showing that they are connected to other institution faculty members on phone. 
3. Generation Y preferred to attend phone calls (36.9\%) of other institution faculty members than within the institution which indicates that they are connected to other faculty members. Reading messages (46.4\%) within and $(43.9 \%)$ outside the institution difference indicates that the generation is connected to the institution but not much comfortable in attending phone calls within the institution.

\section{The contribution of the study}

The study revolved around knowledge donation and knowledge collection. In this study, specifically informal ways of transfer of knowledge are analyzed. These are helpful in the development of the education sector as it will lead to the creation of innovative learning which later becomes knowledge. Augmentation of higher education will lead to the comprehensive development of society. Students will become more employable and hence generation of new employment opportunities. Other implied contribution of this study is that in today's time society is facing the problem of seclusion if not taken care it can later take the form of depression. The root cause is people hardly interact rather they prefer surfing the internet. Light interaction will encourage and inspire people to exchange knowledge. People will feel that they are given importance. The outcome will be confident, motivated and intellectually sound people in the society.

\section{Suggestions}

On the basis of the results, it can be suggested that educational institution should incline their interest towards the encouragement of communication within the institution. Specifically, generation Y who showed higher interaction levels outside their institution and somewhere it is indicating that their opinion is not given value as it is outside the institution. Generation X who is looking for comfort because of their family responsibilities they should be encouraged to take an active part in sharing of knowledge outside their institution. Baby Boomers should be considered as those assets of the institution who will sooner or later leave the institution. So higher education institutions should be accountable for maximum knowledge should be taken from experienced faculty members which they have gathered while working so many years. This all can be achieved with an environment which can foster sharing of ideas and information without any fear or hesitation. Occasionally informal gathering of all the faculty members of a different generation will meet this motive.

\section{Conclusion:-}

It is very important for the higher education to create, generate and disseminate knowledge. In this study, it was discussed that tacit knowledge is sometimes overlooked by the institutions. Study revealed that all the three generations are different in sharing knowledge within and outside the university or college. The frequency differs within and outside the university or college is because of their cohort characteristic differences. In order to foster an environment where knowledge can be shared, generational problems and issues should be considered. There cannot be a stipulated strategy to tackle the problem as the demography of all the university or college is different. Keeping in mind the proportion of the generation institutions should design a framework for sharing of knowledge.

\section{References:-}

1. Austin, A. E. (2016). Preparing the Next Generation of Faculty. The Journal of Higher Education, 73 (1: The Faculty in the New Millennium), 94-122.

2. Bhusry, M., \& Ranjan, J. (2012). Enhancing the teaching-learning process: a knowledge management approach. International Journal of Educational Management, 313-329.

3. Chen, C.-J. (2010, May). To give or to receive? Factors influencing members' knowledge sharing and community promotion in professional virtual common. Information and Management, 226-236.

4. Ding, C. Q., \& Xue, J. (2015). Research on Tacit Knowledge-Sharing Willingness in. International Conference of Electrical, Automation and Mechanical Engineering (EAME 2015) (pp. 553-556). Nanjing, China: Atlantis Press.

5. Dumey, J. C., \& Garletti, A. (2015). Public sector knowledge management: A structured literature review. Journal of Knowledge Management, 19 (3), 530-558.

6. Frolich, N., \& Stensaker, B. (2010). Student recruitment strategies in higher education: promoting excellence and diversity? International Journal of Educational Management, 24 (4), 359-370.

7. Gho, S. C. (2002). Managing effective knowledge transfer: an integrative framework and some practice implications. Journal of Knowledge Management, 6 (1), 23-30. 
8. Holste, J. S. (2009). Trust and tacit knowledge sharing and use. Journal of Knowledge Management, 14 (1), 128-140.

9. Husseini, S. A., \& Elbeltagi, I. (2015). Knowledge Sharing Practices as a Basis of Product. International Journal of Social Science and Humanity, 5, 182-185.

10. Johnson, S. A., \& Romenallo, M. N. (2005). Generational Diversity: Teaching and Learning Approaches. Nurse Educator, 30 (5), 212-216.

11. Kamasak, R. (2010). The influence of knowledge sharing on innovation. European Business Review, 22 (3), 306-317.

12. Landoli, L., \& Quinto, I. (2012). A debate dashboard to enhance online knowledge sharing. VINE , 42 (1), $67-$ 93.

13. Lin, H. F. (2007). Knowledge sharing and firm innovation capability: an empirical study. International Journal of Manpower, 28 (4), 315-332.

14. Mansor, Z. D., \& Mustaffa, M. (2015). Motivation and Willingness to Participate in Knowledge Sharing Activities Among Academics in a Public University. INTERNATIONAL ACCOUNTING AND BUSINESS CONFERENCE IABC (pp. 286-293). Putra Malaysia: Elsevier.

15. Susanty, A. I., \& Wood, D. C. (2011). THE MOTIVATION TO SHARE KNOWLEDGE OF THE EMPLOYEES. International Conference on Social Science and Humanity IPEDR (pp. 159-162). Singapore: IACSIT Press.

16. Tessie H.H. Herbst, P. D. (2011). Leadership effectiveness in Higher Education: Managerial self-perceptions versus perceptions of others. SA Journal of Industrial Psychology, 14 pages.

17. Vries, R. E., \& Hoff, B. V. (2006). Explaining Knowledge Sharing The Role of Team Communication Styles, Job Satisfaction, and Performance Beliefs. Communication Research, 115-135.

18. Zaquot, F., \& Abbas, M. (2012). Towards a model for understanding the influence of the factors that stimulate university students' engagement and performance in knowledge sharing. Library Review, 61 (5), 345-361. 